\title{
Double localization of a non-anastomotic pseudoaneurysm after an axillofemoral bypass: a case report and review of the literature
}

Badr Bensaid*, Tarek Bakkali, Youssef Tijani, Samir Elkhalloufi, Brahim Lekehal, Yassir Sefiani, Abess El Mesnaoui and Younes Bensaid

\begin{abstract}
Background: A traumatic non-anastomotic pseudoaneurysm is a rare complication of an axillofemoral bypass graft. Fewer than 20 cases have been reported in the literature. Our case is unusual in that we report a double localization of this complication.

Case presentation: We report the case of a 60-year-old Arabic male patient who was diagnosed with two hematomas in the trajectory of his axillofemoral bypass secondary to a traumatism. The diagnosis of a non-anastomotic pseudoaneurysm was retained considering the results of a computed tomography angiography scan, which showed the double localization of the pseudoaneurysm. Surgical management consisted of flattening the pseudoaneurysm along with the interposition of a prosthetic segment. There were no postoperative complications and our patient was well 3 years after discharge.

Conclusions: Non-anastomotic pseudoaneurysm is a rarely described complication of a axillofemoral bypass graft. To the best of our knowledge, a double localization has not been described in the literature before. Minimally invasive techniques as a treatment option are being widely used as an alternative to open repair.
\end{abstract}

Keywords: Non-anastomotic pseudoaneurysm, Axillofemoral bypass, Ringed graft, Interposition graft, Case report

\section{Background}

In 1963 Blaisdell and Hall were the first to describe an axillofemoral bypass graft (AFBG); it has since become one of the commonly used surgical techniques. It is routinely used for lower extremity occlusive disease in selected situations. Its major indications are a hostile abdomen, multiple previous abdominal surgeries, a prohibitive risk from general anesthesia, and severely sick patients [1].

The most commonly known complications of this technique are thrombosis and infection. Other complications, such as postoperative axillary anastomosis disruption, have also been reported. According to some retrospective studies, postoperative axillary anastomosis disruption can

\footnotetext{
* Correspondence: bensaidbadr8@gmail.com

Vascular Surgery Department, Ibn Sina Hospital, Mohamed V University, NAHDA Avenue, Box 45, App 21, Rabat, Morocco
}

occur in $5 \%$ of the cases [2], especially in the first few weeks after surgery [3]. Non-anastomotic pseudoaneurysm (PSA) is considered a rare complication of AFBG. Few cases have been described in the literature [4-6].

Our case report not only describes a traumatic PSA at the mid-shape of an AFBG but also adds to the literature an unusual case with a double localization.

\section{Case presentation}

A 60-year-old Arabic male patient presented to our emergency department with pulsating masses in his right torso 5 days after a traumatism secondary to a cart accident. A review of his medical chart revealed that he had undergone an AFBG about 2 months earlier for lower limb revascularization. The indication for the AFBG was an occlusion in his primitive iliac artery, diagnosed by Doppler ultrasonography and computed tomography 
(CT) angiography. At that time, AFBG was chosen as the treatment of choice because of our patient's low ventricular ejection fraction (35\%) in addition to several comorbidities, including diabetes (type 2 diabetes mellitus treated with insulin) and high blood pressure (for which he was being treated), and his long history of tobacco use (active smoker for about 40 years). Revascularization was performed using an 8-mm, reinforced, thin-walled, fluorinated ethylene-propylene-ringed, expanded polytetrafluoroethylene (ePTFE) graft.

During the current admission, we found two masses along the side of the AFBG of about $6 \mathrm{~cm}$ and $4 \mathrm{~cm}$ each. On examination, these masses were painful and tender. The first mass was located at the level of the nipple line, while the second was located at the level of the umbilical line. The overlying skin was tense and blanched. Doppler ultrasonography demonstrated that his left femoral pulse and left distal extremity pulses were absent with monophasic flow. The strength and sensation in his left leg were intact. There were no signs of compartment syndrome. There was a left anterolateral midrib fracture deep to the hematoma. CT of his chest with intravenous contrast showed two non-anastomotic PSAs in the trajectory of the AFBG graft (Fig. 1). His

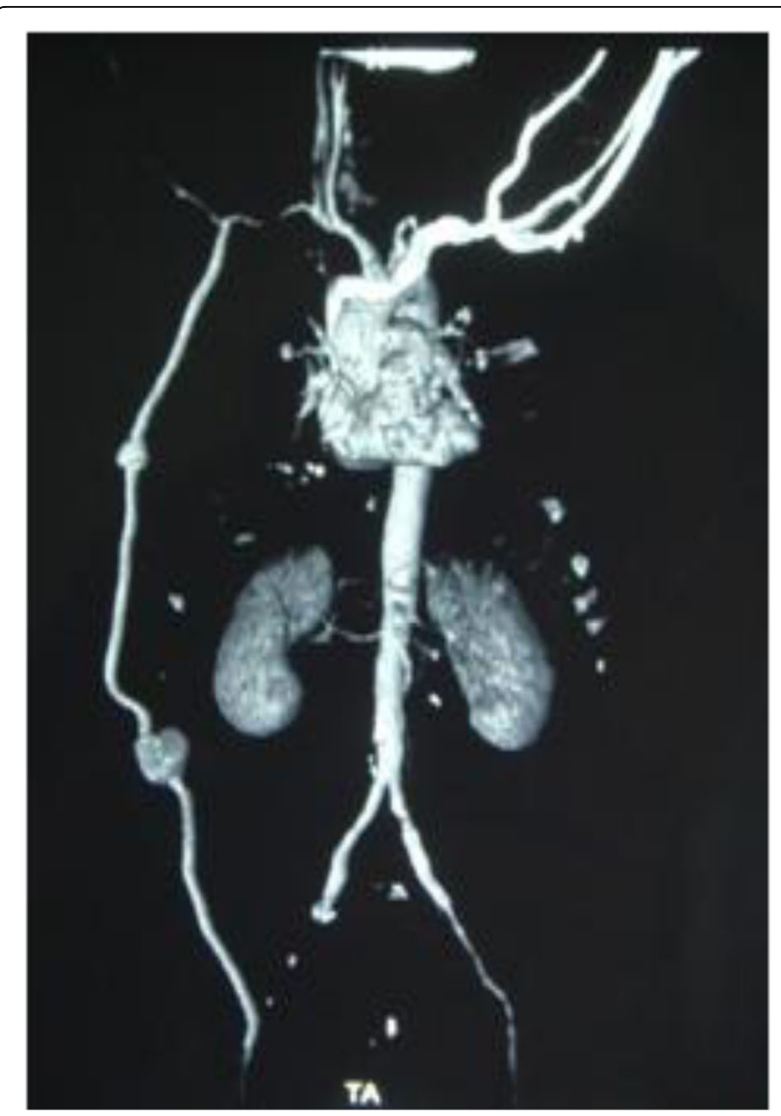

Fig. 1 Three-dimensional vessel reconstruction from biplane angiogram: double localization of non-anastomotic pseudoaneurysms hemoglobin level was $10.0 \mathrm{~g} / \mathrm{dL}$, prothrombin time was 1.6 seconds, partial thromboplastin time was 29.7 seconds, and platelet count was $160,000 / \mathrm{mL}$. His renal function was normal with a creatinine clearance rate of $70 \mathrm{mg} / \mathrm{m}^{2}$. Echocardiography showed a ventricular ejection fraction of $40 \%$. Consequently, our patient underwent urgent operative repair. The surgical treatment involved flattening the PSAs and the interposition of a prosthetic segment (Figs. 2 and 3). On completion of the procedure, his left femoral pulse was palpable and pedal pulses were present on Doppler ultrasonography. Our patient recovered uneventfully and was well 3 years after discharge.

\section{Discussion}

An AFBG is a routine surgical technique used to revascularize the lower limb. It can be done alone or in conjunction with a femoro-femoral bypass. One of the most interesting benefits of this technique is that it avoids aortic clamping and is associated with low rates of morbidity and mortality when compared with traditional aortobifemoral graft surgery. It also has the advantage that it does not necessarily require general anesthesia [1]. AFBG is therefore a particularly attractive technique for patients with cardiovascular comorbidities.

Despite its benefits, authors have reported lower patency rates for AFBG, estimated to be around $35-71 \%$ at 5 years $[7,8]$. This percentage can be improved when using rings for external support $[8,9]$ and can reach a patency rate of $85 \%$ [9]. Commonly reported complications of this technique are thrombosis, infection, and PSA [2-15]. This latter complication can occur in a variety of locations, the most frequent being at a femoral artery graft anastomoses, which was where the PSAs were localized in our case. Current studies have theorized that this is due to turbulent blood flow that

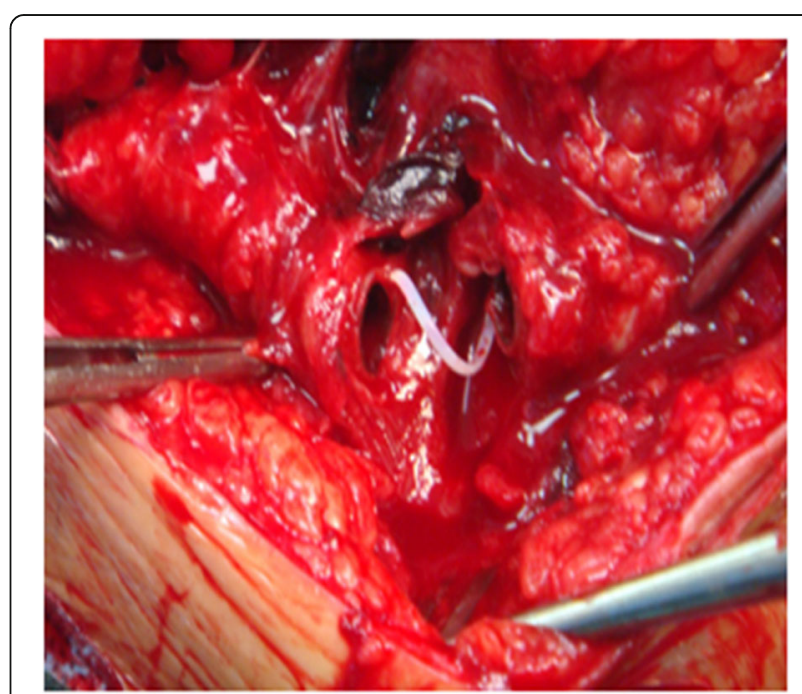

Fig. 2 Intraoperative view of the pseudoaneurysm 


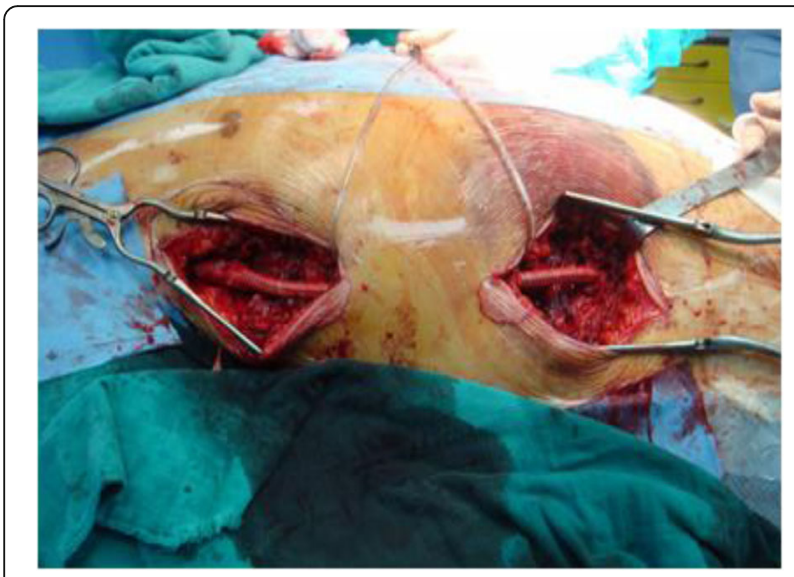

Fig. 3 Intraoperative view after the surgical repair with grafts

progressively weakens the arterial wall of end-to-side anastomoses, promoting the development of anastomotic leaks [10]. PSA occurs in $0.8-2.2 \%$ of revascularization procedures $[11,12]$.

Non-anastomotic PSA is an extremely rare complication. We found few cases reported in our literature review, and none reported more than one localization, which makes our report unusual. The first case of post-traumatic non-anastomotic PSA was described by Buche et al. in 1992 [15]; they reported the case of a 38-year-old male patient with a PSA secondary to a fall 10 months after his axillofemoral bypass. Piazza et al. [4] and Kruger et al. [16] each described a case of non-anastomotic PSA, occurring 12 and 29 months respectively after the AFBG. One case was due to a trauma with a seat belt in a cart accident. Etiologies other than traumatism have also been described; iatrogenic disruption as the cause has been reported by several authors $[4,17,18]$. In our case, the non-anastomotic PSA was secondary to a cart accident.

Ultrasonography is considered a reliable tool to diagnose non-anastomotic PSA; however, its main flaw is that it is an operator-dependent procedure [6]. CT angiography is associated with better sensitivity and specificity rates. It allows more precise diagnosis of PSA, in addition to the diagnosis of collections and signs of inflammation or abscess [6]. Intravascular ultrasonography is also crucial in the diagnosis of PSA because it permits proper vessel sizing and an estimation of the severity of pathology [6]. In our case, ultrasonography was complemented by a CT angiogram that permitted an accrual diagnosis.

With regards the treatment and management of this complication, surgical open repair has had excellent outcomes in the first reported cases of non-anastomotic PSA [5-15], and it is still widely used. More recently, minimally invasive techniques have been described in the repair of non-anastomotic PSA. Grochow et al. were the first to describe this technique in 2008 [17]. Since then, other cases have been described [18]. The most recently reported case concerned an 82-year-old female patient who presented with a non-anastomotic PSA 15 years after her AFBG; in this case the traumatic PSA was managed via an endovascular approach [6]. In our case, we used an open surgery approach because of the large size of the hematoma, which would not have been easily managed with an endoscopic technique. We were able to repair both of the PSAs with excellent outcomes; our patient remains well 3 years after surgery.

Routine follow-up of these grafts after placement is recommended by most authors, even after a successful repair. Our patient is still attending follow-up appointments.

\section{Conclusions}

A non-anastomotic PSA is a rarely described complication of AFBG; traumatism is the most common etiology. With the advent of new imaging methods, diagnosis of PSA has become easier. Surgery is the standard of care for this entity; however, minimally invasive techniques are being widely used as an alternative to open repair.

\section{Abbreviations \\ AFBG: Axillofemoral bypass graft; CT: Computed tomography; \\ PSA: Pseudoaneurysm}

\section{Acknowledgements \\ The authors would like to thank Dr Jihane Khalil for her precious help in correcting this article.}

\section{Funding}

There are no funding sources to be declared.

\section{Availability of data and materials}

Supporting material is available if further analysis is needed.

\section{Authors' contributions}

BB treated the patient, collected and analyzed the available data, and wrote most of the manuscript with TB. SE was involved in drafting the manuscript and revising it critically. YS and BL contributed to the conception and design of the manuscript. AE participated in collecting the available data for the literature review. YB gave final approval of the version to be published. YT was involved in coordination with SE in drafting the manuscript. All authors read and approved the final manuscript.

\section{Competing interests}

The authors declare that they have no competing interests.

\section{Consent for publication}

Written informed consent was obtained from the patient for publication of this case report and any accompanying images. A copy of the written consent is available for review by the Editor-in-Chief of this journal.

\section{Ethics approval and consent to participate}

Ethics approval has been obtained to proceed with the current study. Written informed consent was obtained from the patient for participation in this publication.

Received: 10 February 2016 Accepted: 21 November 2016 Published online: 04 January 2017 


\section{References}

1. Blaisdell FW, Hall AD. Axillary-femoral artery bypass for lower extremity ischemia. Surgery. 1963;54:563-8.

2. Taylor Jr LM, Park TC, Edwards JM, et al. Acute disruption of polytetrafluoroethylene grafts adjacent to axillary anastomoses: a complication of axillofemoral grafting. J Vasc Surg. 1994;20(4):520-6.

3. Yeager RA, Taylor Jr LM. Axillary artery anastomosis to avoid axillofemoral bypass disruption. Semin Vasc Surg. 2000;13(1):74-6.

4. Piazza D, Ameli FM, von Schroeder HP, et al. Nonanastomotic pseudoaneurysm of expanded polytetrafluoroethylene axillofemoral bypass graft. J Vasc Surg. 1993;17(4):777-9.

5. Oz BS, Yilmaz AT, Gunay C, et al. True aneurysm formation in axillofemoral bypass with a reinforced Eptfe graft-a case report. Vasc Endovascular Surg. 2002;36(4):327-9.

6. Mousa AY, Nanjundappa A, Abu-Halimah S, et al. Traumatic nonanastomotic pseudoaneurysm of axillofemoral bypass graft: a case report and review of the literature. Vasc Endovascular Surg. 2013;47(1):57-60.

7. Liedenbaum MH, Verdam FJ, Spelt D, et al. The outcome of the axillofemoral bypass: a retrospective analysis of 45 patients. World J Surg. 2009;33(11):2490-6.

8. Taylor Jr LM, Moneta GL, McConnell D, et al. Axillofemoral grafting with externally supported polytetrafluoroethylene. Arch Surg. 1994;129(6):588-94.

9. Schneider JR, McDaniel MD, Walsh DB, et al. Axillofemoral bypass: outcome and hemodynamic results in high-risk patients. J Vasc Surg. 1992;15(6):952-62.

10. Ylönen K, Biancari F, Leo $E$, et al. Predictors of development of anastomotic femoral pseudoaneurysms after aortobifemoral reconstruction for abdominal aortic aneurysm. Am J Surg. 2004;187(1):83-7.

11. Gherman C, Mironiuc A, Olinic D, et al. Aortic anastamotic pseudoaneurysm. a complication of abdominal aortic surgery. Timisoara Med J. 2003;53(3-4): 279-82.

12. Anthony Yuk-Wai Wu, Wissam Al-Jundi, Zehra Ziadi, Mohamed Barkat, Amjad Khushal. Huge anastomotic femoral pseudoaneurysm following aortobifemoral bypass. BMJ Case Reports 2011; doi: 10.1136/bcr.07.2010.3160.

13. Daar AS, Finch RA. Graft avulsion: an unreported complication of axillofemoral bypass grafts. Br J Surg. 1978;65(6):442.

14. Huang CK, Lu MS, Chang JP, et al. Axillary anastomotic disruption after axillofemoral bypass. J Emerg Med. 2007:32(3):305-7.

15. Buche $M$, Noirhomme $P$, Devaux $P$, et al. Posttraumatic false aneurysm of axillofemoral bypass graft. J Vasc Surg. 1992;16(3):498-500.

16. Kruger K, Landwehr P, Kristen F, et al. Unusual pseudoaneurysm of an axillofemoral bypass caused by seat belt trauma: case report. J Trauma. 1999:46(1):189-91.

17. Grochow RM, Raffetto JD. Chronic traumatic pseudoaneurysm of polytetrafluoroethylene axillofemoral bypass graft in a quadriplegic patient. Ann Vasc Surg. 2008;22(5):688-91.

18. Shibutani S, Obara H, Kakefuda T, et al. Nonanastomotic pseudoaneurysm with complete disruption of an expanded polytetrafluoroethylene axillofemoral bypass graft. Ann Vasc Surg. 2012;26(3):422. e9-422.e12.

\section{Submit your next manuscript to BioMed Central and we will help you at every step:}

- We accept pre-submission inquiries

- Our selector tool helps you to find the most relevant journal

- We provide round the clock customer support

- Convenient online submission

- Thorough peer review

- Inclusion in PubMed and all major indexing services

- Maximum visibility for your research

Submit your manuscript at www.biomedcentral.com/submit 